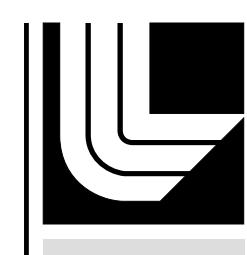

LAWRENCE LIVERMORE N A T IO N A L LABORATORY

Design and Use of a Novel Apparatus for Measuring Capsule Fill Hole Conductance

R. M Seugling, W. W. Nederbragt, J. L.

Klingmann, S. Edson, J. Reynolds, R. Cook

January 4, 2007

Fusion and Science Technology 
This document was prepared as an account of work sponsored by an agency of the United States Government. Neither the United States Government nor the University of California nor any of their employees, makes any warranty, express or implied, or assumes any legal liability or responsibility for the accuracy, completeness, or usefulness of any information, apparatus, product, or process disclosed, or represents that its use would not infringe privately owned rights. Reference herein to any specific commercial product, process, or service by trade name, trademark, manufacturer, or otherwise, does not necessarily constitute or imply its endorsement, recommendation, or favoring by the United States Government or the University of California. The views and opinions of authors expressed herein do not necessarily state or reflect those of the United States Government or the University of California, and shall not be used for advertising or product endorsement purposes. 


\title{
DESIGN AND USE OF A NOVEL APPARATUS FOR MEASURING CAPSULE FILL HOLE CONDUCTANCE
}

\author{
Richard M. Seugling, Walter W. Nederbragt, Jeffery L. Klingmann, \\ Stanley L. Edson, Jack L. Reynolds, and Robert C. Cook \\ Lawrence Livermore National Laboratory, Livermore, CA 94550 \\ seugling2@1ln1.gov
}

Description and results of a novel apparatus for determining the flow conductance through a laser drilled hole in a spherical shell for inertial confinement fusion experiments are described. The instrument monitors the pressure of an enclosed volume containing the laser drilled capsule as air bleeds through the hole into the shell. From these measurements one obtains the conductance of the fill hole. This system has proven to be a valuable tool for verifying the conductance into the capsule in a timely and nondestructive manner.

\section{INTRODUCTION}

Inertial confinement fusion (ICF) targets are complex assemblies developed from a number of components. In general, indirect drive ICF ignition targets are comprised of a capsule with a relatively thick wall or ablator, filled with a deuterium $\left(\mathrm{D}_{2}\right)$ or deuterium/tritium (DT) fuel, and contained in a cylindrical hohlraum designed to convert laser radiation to $\mathrm{x}$-ray radiation, which acts as the driver for ignition. ${ }^{1}$ The baseline ignition design ${ }^{2}$ for the National Ignition Campaign (NIC) is a roughly $2 \mathrm{~mm}$ diameter Be capsule with a $160 \mu \mathrm{m}$ wall thickness. The design includes a small hole, about $5.0 \mu \mathrm{m}$ in diameter, through the ablator as a means of providing the required fuel. Dimensional requirements of the fill hole are driven by a number of factors, but the most prevalent is the need to minimize the mass defect during the implosion while still allowing enough time to evacuate and subsequently fill the target capsule. The apparatus described in this paper was developed to verify and measure flow into the capsule before it is assembled into a complete target.

DT fuel is to be delivered to the ablator through a small tube rigidly fixed to the capsule as illustrated in Fig. 1. The fill tube is an approximately $10 \mu \mathrm{m}$ diameter glass or polyimide ${ }^{3}$ tube drawn down to size from a larger initial diameter. Currently, the spherical shells are fabricated by sputtering copper-doped-beryllium onto a plasma polymer $(\mathrm{CH})$ mandrel. ${ }^{4,5}$ The $5 \mu \mathrm{m}$ diameter through hole is laser drilled ${ }^{6}$ through both the Be and $\mathrm{CH}$ walls. In addition to the $5 \mu \mathrm{m}$ diameter through hole, a 12 to $15 \mu \mathrm{m}$ diameter counterbore, up to $40 \mu \mathrm{m}$ deep, is formed at the outside of the capsule to aid in affixing the fill tube. Focused ion beam (FIB) milling is presently being used to manufacture this counterbore after laser drilling of the fill hole and pyrolysis to remove the plastic mandrel has been completed.?

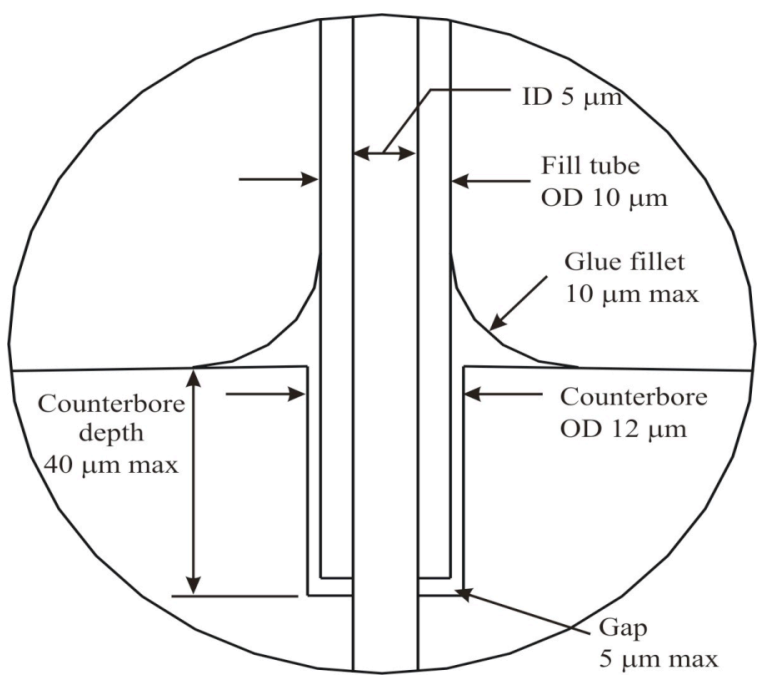

Figure 1. ICF fill tube geometry for baseline ignition target design. A $10 \mu \mathrm{m}$ diameter fill tube inserted into 12 $\mu \mathrm{m}$ diameter $20 \mu \mathrm{m}-40 \mu \mathrm{m}$ deep counterbore attached with $<3$ picoliter of adhesive.

Knowing the flow rate through the fill hole is important to verify capsule flow characteristics prior to assembly. Due to the number of process steps and the complexity of the target assemblies, verifying flow into the capsule prior to assembly is critical to both function and cost; the flow-measuring apparatus described in this report meets this need. 
This apparatus monitors the time required to force air through the laser drilled hole by generating a pressure difference between the interior and exterior of the capsule. Assuming an incompressible fluid and laminar flow, Poiseuille flow through a pipe is used to approximate the flow characteristics through the hole in the Be capsule. A pressure gradient is developed by a spring loaded piston that rapidly compresses the volume inside the chamber. The change in pressure is measured via the deflection of a polyimide diaphragm, monitored with a non-contact laser-displacement probe. By inserting a laser drilled capsule into the apparatus and monitoring the pressure fluctuation during and after compression, a relative measure of the flow rate through the laser hole can be calculated. The time for pressure equalization, when compared to a sample of known conductance, is a qualifying measure of the performance of a given capsule and will be used as an acceptance procedure for quality control purposes.

The design and theory of the conductance instrument is described in this report as well as results expressing the various flow rates encountered given different geometries. However, the theoretical analysis presented is a simplified approximation indicating the variation in important parameters, such as hole diameter, and does not represent a means of accurately measuring or predicting flow rates. Quantification of results are made relative to a reference sample with well characterized geometry.

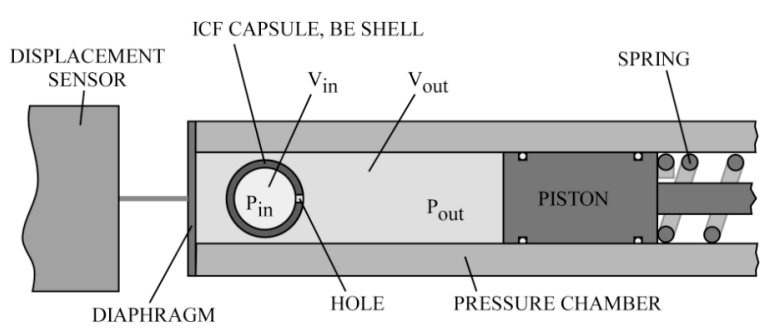

Figure 2. Conceptual illustration of the experimental hardware. Drilled capsule placed into compression chamber while displacement sensor measures deflection of a diaphragm during piston compression.

\section{CONCEPTUAL DESIGN AND THEORY}

As shown in Fig. 2, the capsule is placed in a chamber that can be pressurized quickly via a springloaded piston. Upon pressurization, a diaphragm on the opposite side of the chamber deflects under pressure. The deflection of the diaphragm can be measured and provides an indirect measurement of the internal pressure of the chamber, $P_{\text {out }}$ Immediately after pressurization, the chamber will jump above atmospheric pressure; however, the pressure inside of the capsule will start at one atmosphere and gradually increase until the pressure in the capsule and chamber equalize. The radius of the hole in the capsule, $a$, length of the hole in the capsule, $l$, starting pressure of the chamber, $P_{\text {out }}$ at $t=0 \mathrm{~s}$, the volume of the capsule, $V_{\text {in }}$, and volume of the chamber not including the capsule, $V_{\text {out }}$, determine how fast equalization occurs.

Assuming an incompressible fluid and laminar flow, Poiseuille flow ${ }^{8,9}$ through a pipe can be used to approximate the flow characteristics through the hole in the Be capsule,

$$
\frac{d V}{d t}=A\left(P_{\text {out }}-P_{\text {in }}\right),
$$

where $A=\pi a^{4} / 8 \eta l$ and $\eta$ is the viscosity of air.

Cook, et al. ${ }^{7}$ has solved a similar problem. For flow into the capsule it was shown that

$$
\frac{d P_{\text {in }}}{d t}=\frac{A P_{\text {out }}^{2}}{V_{\text {in }}}-\frac{A P_{\text {out }} P_{\text {in }}}{V_{\text {in }}} .
$$

In the case treated by Cook, $P_{\text {out }}$ was taken as a constant. Such is not the case for our application. But it is clear that

$$
\begin{aligned}
P_{\text {in }} & =\frac{n_{\text {in }} R T}{V_{\text {in }}}=\left(n_{\text {total }}-n_{\text {out }}\right) \frac{R T}{V_{\text {in }}} \\
= & \frac{R T n_{\text {total }}}{V_{\text {in }}}-\frac{V_{\text {out }}}{V_{\text {in }}} P_{\text {out }} .
\end{aligned}
$$

Then Eq. (2) becomes

$$
\frac{d P_{\text {out }}}{d t}=C_{1} P_{\text {out }}-C_{2} P_{\text {out }}^{2},
$$

where $C_{1}=\frac{A R T n_{\text {total }}}{V_{\text {in } V_{\text {out }}}}$ and $C_{2}=\frac{A}{V_{\text {out }}}+\frac{A}{V_{\text {in }}}$.

Solving this differential equation gives

$$
P_{\text {out }}(t)=\frac{1}{\frac{C_{2}}{C_{1}}+\left(\frac{1}{P_{\text {out }}(0)}-\frac{C_{2}}{C_{1}}\right) e^{-C_{1} t}},
$$




$$
P_{\text {out }}(t)=\frac{1}{\frac{C_{2}}{C_{1}}+\left(\frac{1}{P_{\text {out }}(0)}-\frac{C_{2}}{C_{1}}\right) e^{-t / \tau}},
$$

where $\tau=\left(\frac{8 \eta \cdot V_{\text {in }} V_{\text {out }}}{\pi R T n_{\text {total }}}\right) \frac{l}{a^{4}}$.

Also, note that $C_{1} / C_{2}$ is the equilibrium pressure of the system.

Using typical values, $V_{\text {out }}=2 V_{\text {in }}, P_{\text {out }}(0)=2 \mathrm{~atm}$ and $P_{\text {in }}(0)=1 \mathrm{~atm}$, several pressurization equalization curves have been plotted (see Fig. 3).

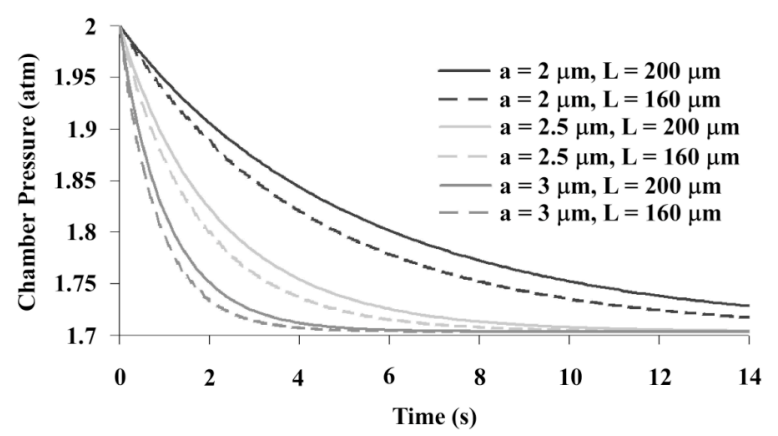

Figure 3. Calculated equalization curves for a variety of through hole radii and lengths, illustrating the sensitivity of the measurement to changes in hole geometry.

In order for this apparatus to be of useful, the chamber pressure needs to be measured. Designing a small pressure chamber that can accommodate a pressure transducer is impractical; hence an indirect method of measuring pressure (deflection of a diaphragm) is used. The following equation shows the relationship between the deflection of the diaphragm and the chamber pressure, ${ }^{10,11}$

$$
P(y)=\frac{E t_{\mathrm{dia}}^{4}}{R^{4}}\left[\frac{16 y}{3\left(1-v^{2}\right) t_{\mathrm{dia}}}+\frac{(7-v) y^{3}}{3(1-v) t_{\mathrm{dia}}^{3}}\right] .
$$

\section{CURRENT SYSTEM DESIGN}

Many details had to be worked out when the conceptual design was converted into a functioning apparatus. The chamber had to be simple to assemble so that capsules could be easily inserted and removed. The chamber also had to seal well and have a consistent internal volume so that the test results would be repeatable. This was accomplished using small O-rings in two key areas and a few small screws to hold the assembly together. Also, to protect the capsule, the capsule had to be held outside of the range of the piston; this was achieved by inserting a pin between the capsule and piston to prevent the capsule from moving into the piston's range, but allowing the chamber gas to freely move inside of the chamber.

The spring-loaded piston had to quickly pressurize the chamber. Moreover, to compensate for unknowns (e.g., variation in the chamber volume caused by machining tolerances and unknown gas compression dynamics) the stroke of the piston needed to be adjustable. The largest unknown was where the gas compression dynamics would fall; it would be somewhere between an adiabatic compression and an isothermal compression. Adjustability was designed in using a stroke adjustable screw connected to the piston. Consistent loading of the chamber was made possible via a locking pull ring (i.e. the piston gets pulled back until the pull ring pin can be inserted into the piston to hold it in place). When desired, the pull ring can be activated to allow the piston to release.

The mounting hardware needed to be stiff to prevent unwanted motion during use. It also had to allow for adjustment of the displacement sensor for alignment purposes and allow easy access to the piston chamber and pull ring.

As stated previously, the chamber pressure is measured indirectly by measuring the deflection of a diaphragm. Polyimide was chosen as the diaphragm material because it had a measurable displacement under normal operating conditions; yet it was strong enough to withstand pressures above the normal operating conditions. The maximum operating pressure deflects the diaphragm approximately $75 \mu \mathrm{m}$. After pressure equalization, the diaphragm is deflected back down to approximately $62 \mu \mathrm{m}$. Hence, the system needed a displacement sensor with a range greater than $75 \mu \mathrm{m}$ and adequate sensitivity in the normal operating range $(62 \mu \mathrm{m}$ to $75 \mu \mathrm{m})$. Three sensors were considered: a capacitance probe, a confocal laser probe, and a laser triangulation probe. The confocal probe was tried first; it had a resolution of $0.4 \mu \mathrm{m}$ and a sampling frequency of $1.4 \mathrm{kHz}$. It worked, but the signal was noisy. A laser triangulation probe was tried next; it had a resolution of $0.01 \mu \mathrm{m}$ and a sampling frequency of $50 \mathrm{kHz}$. This sensor gave good, clean data; hence, it was used. A highspeed data acquisition system was incorporated to accommodate the high data output of the sensor. The polyimide, initially, caused problems because the 
displacement sensor penetrated the polyimide diaphragm and picked up the shiny surface of the capsule inside of the chamber. This problem was surmounted by placing a thin opaque aluminum coating on the polyimide diaphragm.

\section{CALIBRATION AND PART MEASUREMENT RESULTS}

Although the theory behind the apparatus is well understood, it should be clear that calibration runs are necessary to validate the results of the apparatus because of the large number of variables in play.

Calibration is accomplished using a reference artifact of known geometry. Although a calibration procedure is being used, the absolute accuracy of the measurement is not as critical as timely and nondestructive verification of flow into the capsule prior to assembly. To construct the reference artifact, a polyimide capsule ${ }^{12}$ nominally the size of a NIF baseline design capsule was drilled and a glass tube was inserted into it creating a smooth walled though-hole of known diameter and length. The tube has an inside diameter of $3 \mu \mathrm{m}$ and a length of $50 \mu \mathrm{m}$ with little or no variation of diameter along the given length. To verify the upper and lower bounds of the system, data is also taken with an empty chamber and with a solid capsule of similar dimension to the one being measured. Results of this procedure with the reference capsule are shown in Fig. 4. An approximately $10 \%$ difference was found between the theoretical model and results for this experiment.

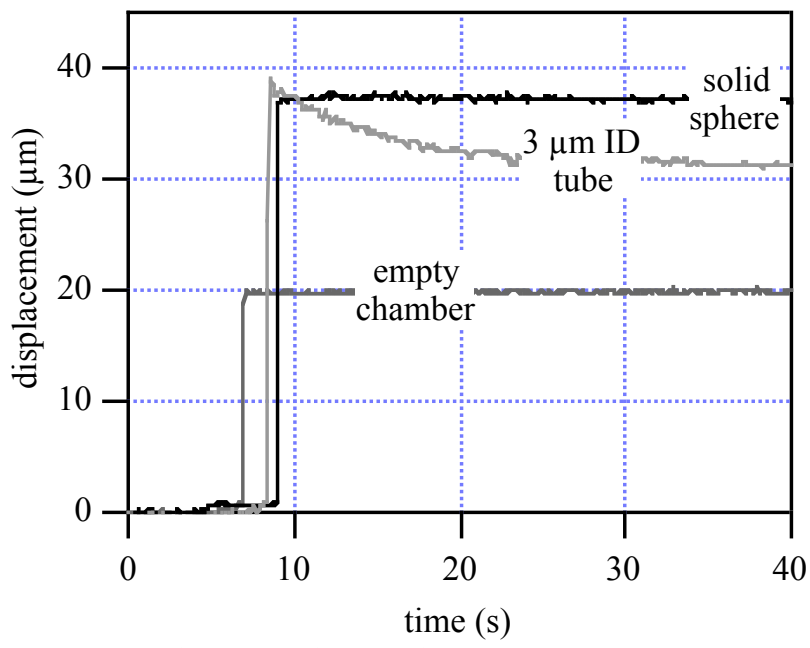

Figure 4. Shown is the conductance apparatus response for an empty chamber, a solid sphere, and a $2 \mathrm{~mm}$ shell fitted with a $3 \mu \mathrm{m}$ ID, $50 \mu \mathrm{m}$ long glass fill tube. The latter was used to calibrate the system.
As mentioned earlier, one of the critical functions of this apparatus is to verify conductance prior to assembly and in between manufacturing processes. Typical results of conductance tests after laser drilling and pyrolysis are shown in Fig. 5. In this example, four out of the five capsules tested had open through holes, while the forth proved to be plugged. It should be noted that the holes in these capsules had larger diameters than that of the reference capsule, and thus the time for pressure equalization was less. In addition, tests conducted before and after the FIB counterbore process have shown that the conductance often changes probably due to redeposition of material in the narrow through hole. As illustrated in Fig. 6, there is a variation in time constant before and after the FIB counterbore process. By taking into account the counterbore depth and solving for the change in through hole radius using Eq. (6), an approximate $0.2 \mu \mathrm{m}$ amount of material has been redeposited on the inner wall.

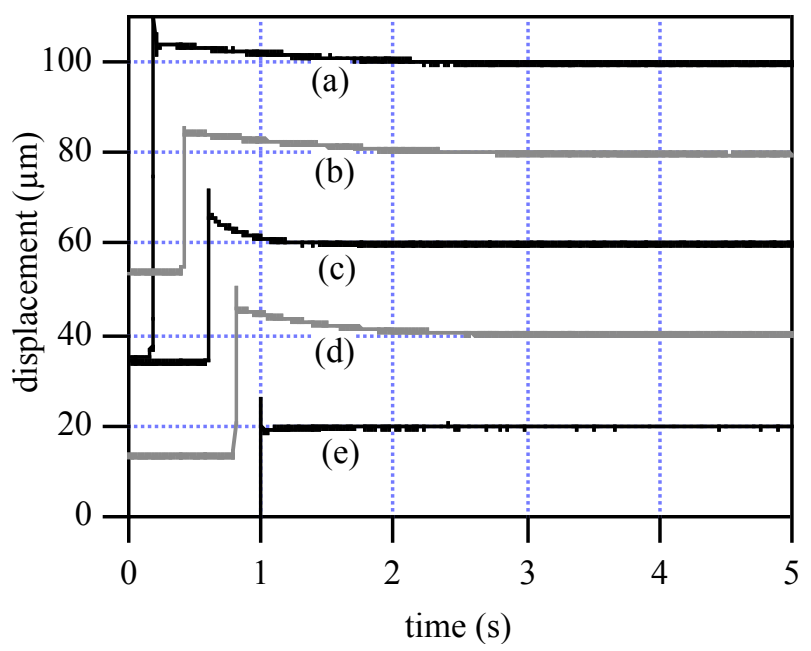

Figure 5. Shown are typical conductance test data for laser drilled holes in Be ablator capsules. Capsules (a) through (d) proved to be open, while capsule (e) was plugged.

\section{CONCLUSIONS}

A flow conductance apparatus has been designed, built and tested to verify the flow into ICF ablator capsules. This system proves to be a valuable asset during the assembly process to help ensure function and minimize target failures. The system simplicity and fairly low cost make it an effective, nondestructive tool. 

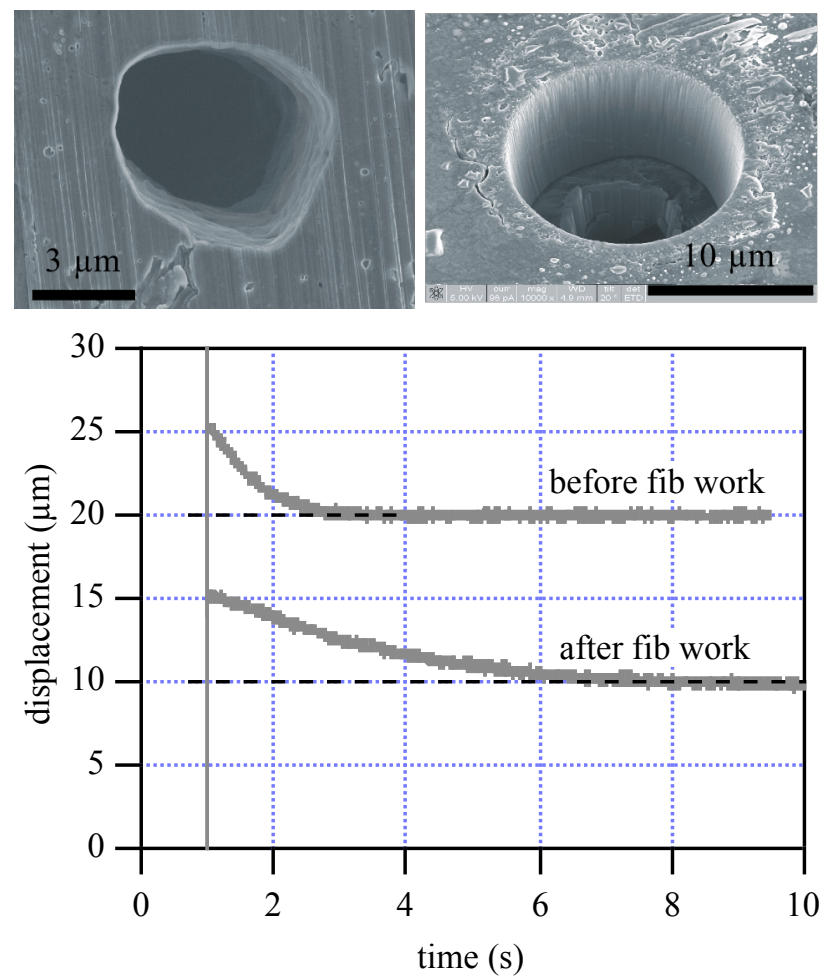

Figure 6. Conductance test results illustrating variation in conductance between process steps. At the top are SEM pictures: left a shell with a laser drilled $\sim 5 \mu \mathrm{m}$ diameter hole; right the same shell after it has had a $\sim 12 \mu \mathrm{m}$ diameter counterbore fibbed. The graph at the bottom shows that the net conductance has decreased due to redeposition of the fibbed material in the small laser drilled hole.

\section{ACKNOWLEDGMENTS}

The authors are pleased to thank Nick Teslich, LLNL, for his work involving FIB machining and SEM imaging. We also thank Abbas Nikroo and Kari Moreno at General Atomics for providing Be shells for our experiments. This work was performed under the auspices of the U.S. Department of Energy by the University of California Lawrence Livermore National Laboratory under contract No. W-7405-Eng-48.

\section{REFERENCES}

1. J. D. LINDL, Inertial Confinement Fusion, The Quest for Ignition and Energy Gain Using Indirect Drive, Springer-Verlag, (1998).

2. S. W. HAAN, et al., "Update on Specifications for NIF Ignition Targets, and Their Rollup into an Error Budget," Fusion Sci. Technol. 49, 553 (2006); S. W.
HAAN, et al, "Update on Specifications for NIF Ignition Targets," Fusion Sci. Technol. this issue.

3. M. TAKAGI, K. SAITO, C. FREDERICK, A. NIKROO, and R. COOK, "Fabrication and Attachment of Polyimide Fill Tubes to Plastic NIF Capsules," Fusion Sci. Technol. this issue.

4. M. McELFRESH, et al., "Fabrication of Beryllium Capsules with Copper-Doped Layers for NIF Targets: A Progress Report," Fusion Sci. Technol. 49, 786 (2006); H. W. XU, et al., "Be Coating on Spherical Surface for NIF Target Development," Fusion Sci. Technol. 49, 778 (2006); H. W. XU, et al., "Beryllium Capsule Coating Development for NIF Targets," Fusion Sci. Technol. this issue.

5. B. W. MCQUILLAN, et al., "The PAMS/GDP Process for Production of ICF Target Mandrels," Fusion Technol. 31, 381 (1997).

6. J. P. ARMSTRONG, A. M. RUBENCHIK, J. GUNTHER, and B. C. STUART, "Micron-Scale Deep Hole Drilling for Beryllium Capsule Fill Applications," Fusion Sci. Technol. 49, 822 (2006).

7. R. C. COOK, S. A. LETTS, S. R. BUCKLEY, and E. FEARON, "Pyrolitic Removal of the Plastic Mandrel from Sputtered Beryllium Shells," Fusion Sci. Technol. 49, 802 (2006).

8. B. R. MUNSON, D. F. YOUNG and T. H. OKISHI, Fundamentals of Fluid Mechanics, pp 367-372, Wiley, New York, (1990).

9. F. M. WHITE, Viscous Fluid Flow, pp 121-123, McGraw-Hill, New York, (1974).

10. J. N. REDDY, Theory and Analysis of Elastic Plates, pp 225-242, Taylor and Francis, Philadelphia, (1999).

11. W. C. YOUNG, Roark's Formulas for Stress and Strain, $6^{\text {th }}$ Ed., pp 432-433, McGraw-Hill, New York, (1989).

12. S. A. LETTS, et al., "Preparation of Polyimide Ablator Coatings Using an Improved Solvent Vapor Smoothing Process," Fusion Sci. Technol. 49, 714 (2006). 